\title{
Studies on Dynamic Change of Dry Cells by Internal Resistance Measurement*
}

\author{
Masataro FUKUDA**, Taketsugu HIRAI** and Haruo MANABE**
}

\begin{abstract}
This report is a part of the fundamental studies on discharge characteristics of manganese dioxide dry cells in the research of "Chemistry of Manganese Dioxide Dry Cells". In former reports (Part $2^{(1)}$ and $8^{(2)}$ ), we reported relations between chemical change of electrolyte and discharge characteristics in dry cells, and we also reported the studies on dynamic change of dry cells by electropotential distribution measurement. The polarization of the positive bobbin will be reported in another report $^{(3)}$.
\end{abstract}

In this report, relations between change of the internal resistances of two kinds of $\mathrm{D}$ size dry cells during the $4 \mathrm{ohm}$ discharge and their dynamic change are mentioned in connection with the results of the reports mentioned above.

First of all, measuring methods of the internal resistances of dry cells; IR drop method (dc method) and alternating current compensation method (ac method) were discussed. And then, change of the internal resistances of $\mathrm{D}$ size dry cells during the $4 \mathrm{ohm}$ discharge were observed by both methods mentioned above. Finally, significances of the internal resistances measured by both methods were discussed, and then dynamic change of dry cells during the discharge were considered with reference to the above conclusion.

Results obtained are as follows.

(1) The internal resistance by dc method decreases and gradually approaches to the definite value, while the discharge current increases. (Fig. 1)

(2) The equivalent series resistance and capacitance to alternating current of D size dry cells can be measured also under discharge condition. Furthermore, both values are constantly independently to the discharge current rate. (Fig. 1 and Fig. 2)

(3) By analysing the frequency characteristics of D size dry cells, we concluded an equivalent

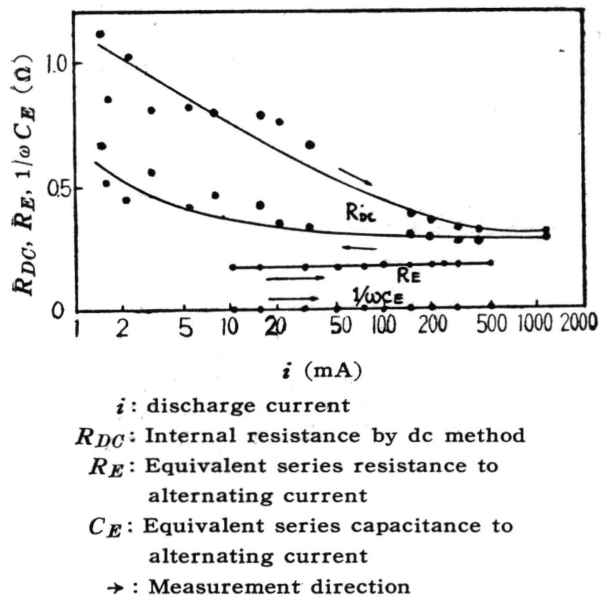

Fig. 1 Relations between $R_{D C}$ or $R_{E}$ or $1 / \omega C_{E}$ of fresh D size dry cells and $i$

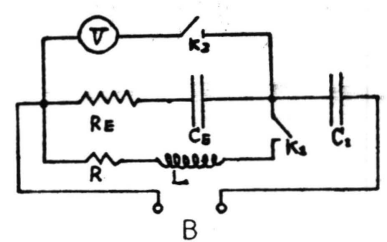

$\boldsymbol{R}_{\boldsymbol{E}}$ : Equivalent series resistance of dry cells ( 10 cells are connected in series)

$C_{E}$ : Equivalent series capacitance of dry cells

$\boldsymbol{R}$ : Equivalent series resistance of load

$L$ : Equivalent series inductance of load $K_{1}, K_{2}:$ Switch

$C_{1}$ : Condenser for checking direct current $(25.5 \mu \mathrm{F})$

$B$ : Impedence bridge

Fig. 2 Measurement device of internal resistance by ac method $\left(R_{A C}\right)$

* Chemistry of Manganese Dioxide Dry Cells (Part 9)

** Central Laboratories, Matsushita Electric Industrial Co., Ltd., Kadoma-cho, Kitakawachi-gun, Osaka, Japan. The original written in Japanese can be seen in J. Electrochem. Soc. Japan, 27, 247 (1959) 
circuit for D size dry cells. (Fig. 3) It will be agreeable that the constant resistance component independent of the frequency in the above mentioned circuit is designated as the internal resistance by ac method.

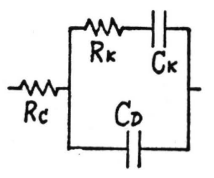

$\boldsymbol{R}_{K}$ : Polarization resistance

$C_{K}$ : Polarization capacitance

$C_{D}$ : Capacitance of electrical double layer

$R_{C}$ : Resistance of electrolyte and other conductor

Fig. 3 An equivalent circuit of D size dry cells considered from Gerischer's result ${ }^{(4)}$

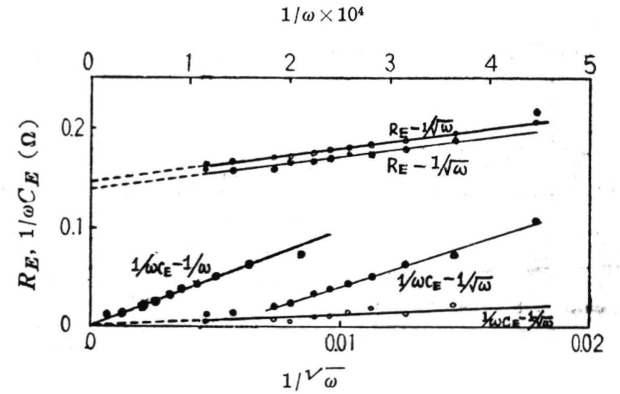

- fresh $\circ$ after $300 \mathrm{~mA}$ discharge for a few seconds

Fig. 4 Relations between $R_{E}$ or $1 / \omega C_{E}$ of D size dry cells and $1 / \sqrt{\omega}$ or $1 / \omega$

(4) The equivalent series capacitances of D size dry cells which had been put aside for a long time increased remarkably, after discharging the cells at $300 \mathrm{~mA}$ for a few seconds. (Fig. 4) This means that polarization capacitances at the negative electrodes of $\mathrm{D}$ size dry cells increased remarkably after the discharge.

(5) The equivalent series resistances of D size dry cells decrease while the frequency increases. This relation can be shown as a linear function to $1 / \sqrt{\omega}$. The internal resistance by ac method, there fore, is equals to the intercept on $y$-axis of this straight line. (Fig. 4)

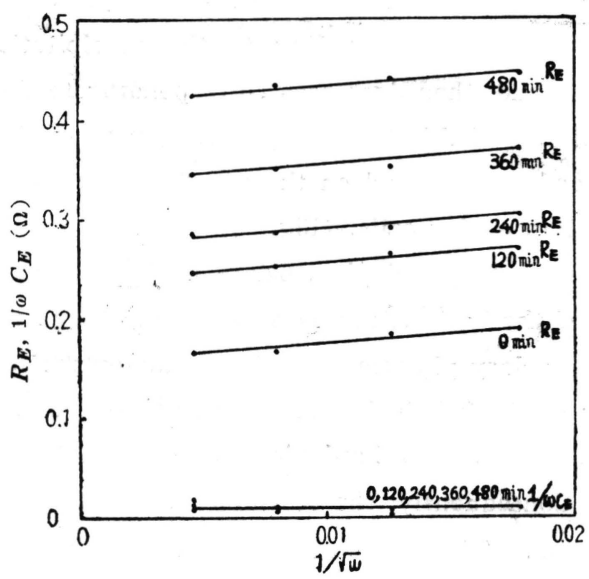

Fig. 5 Relations between $R_{E}$ or $1 / \omega C_{E}$ of D size dry cells and $1 / \sqrt{\omega}$ under $4 \Omega$ continuous discharge

(6) Because the gradient of the straight line in (5) keeps constant during the 4 ohm discharge (Fig. 5), the equivalent series resistance-discharge time curve, which was measured at a definite frequency (500 7500 cycles), is similar in shape to the internal resistance by ac methoddischarge time curve, which is computed by the method mentioned in (5).

(7) The change of internal resistances of D size dry cells during the $4 \mathrm{ohm}$ discharge were observed by dc method and ac method at 1000 cycles. By means of comparing these two internal resistance-discharge time curves, we could conclude the portions where the resistance has changed in dry cells. (Fig. 6 and Fig. 7) 


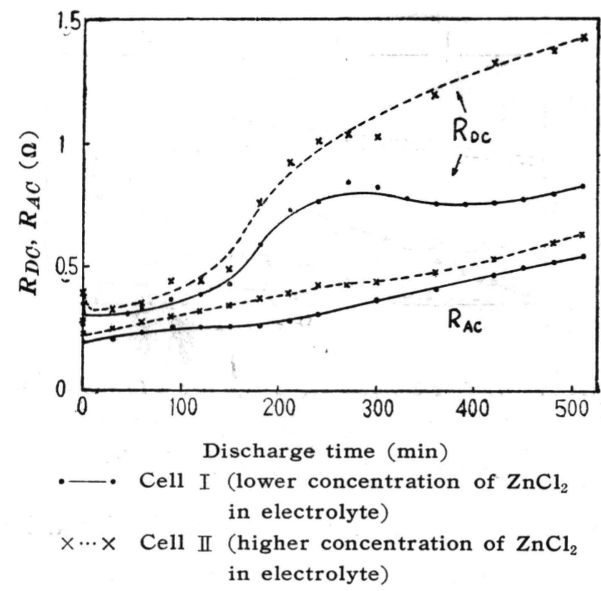

Fig. 6 Changes of $R_{D C}$ and $R_{A C}$ during $4 \Omega$ continuous discharge

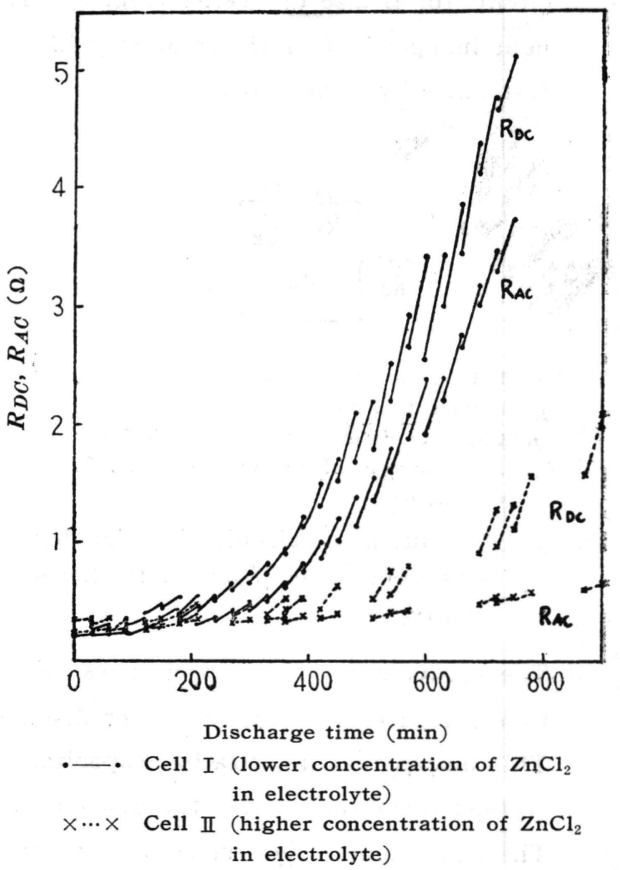

Fig. 7 Changes of $R_{D C}$ and $R_{A C}$ during $4 \Omega$ intermittent discharge

(8) In the continuous discharge, the resistance of electrolyte on a very thin outer layer of the bobbin increases temporarily corresponding to the precipitation of di-ammino zinc chloride $\left(\mathrm{ZnCl}_{2} \cdot 2 \mathrm{NH}_{3}\right)$ crystals, and then decreases corresponding to the dissolution of the precipitation. Some characteristics of this temporary development of the resistance; the starting time and duration, shape and size depend on the concentration and the quantity of zinc chloride $\left(\mathrm{ZnCl}_{2}\right)$ in the electrolyte of dry cells. (Fig. 6)

(9) In the intermittent discharge ( $30 \mathrm{~min} /$ day, 6 days/week), the resistance to electronic current in the inner-most layer of the bobbin increases as the discharge time. This increase is supposed to be an inevitable secondary phenomenon as a result of the following process. (Fig. 7) The very thin outer layer of the bobbin becomes hard at first corresponding to the precipitation of $\mathrm{ZnCl}_{2} \cdot 2 \mathrm{NH}_{3}$ crystals. Then, this hardening phenomenon gradually proceeds into the inner layer of the bobbin. Consequently, the resistance to electronic current in the inner-most layer of the bobbin increases. The concentration and the quantity of $\mathrm{ZnCl}_{2}$ in the electrolyte of dry cells, therefore, have an appreciable effect on the change of the internal resistances of dry cells during the discharge.

(Received 17 th, February 1959)

\section{Literature :}

(1) Masataro Fukuda: National Technical Report (Matsushita Electric Industrial Co., Ltd., Osaka, Japan), 3, 207 (1957)

(2) Masataro Fukuda, Taketsugu Hirai: To be published in National Technical Report (Matsushita Electric Industrial Co., Ltd., Osaka, Japan)

( 3 ) Masataro Fukuda, Taketsugu Hirai, Haruo Manabe: Unpublished.

(4) H. Gerischer: Z. physik. Chem., 158, 289 (1951) 